\title{
Blockchain and its application to accounting
}

\author{
Eladio Pascual Pedreño ${ }^{1}$ (D), Vera Gelashvili² (iD), Laura Pascual Nebreda ${ }^{2}$ (iD \\ ${ }^{1}$ University of Extremadura (Spain) \\ ${ }^{2}$ King Juan Carlos University (Spain) \\ eladiopp@unex.es,vera.gelashvili@urjc.es,laura.pascual@urjc.es
}

Received September, 2019

Accepted May, 2021

\begin{abstract}
Purpose: In recent years Bitcoin has revolutionized the financial world. Its birth was made possible thanks to an innovative combination of certain pre-existing technology in computer networks and cryptography, which led to the existence of a transparent, reliable and immutable record of transactions, a large shared ledger: Blockchain. Several studies analyse the application or future application of Blockchain in different industries. The application of Blockchain in accounting is one of the most debated, since it is a shared accounting record and it is anticipated that its application could change the mission of accountants or even auditors. Therefore, the main objective of this work is to analyze the existing literature on the importance of Blockchain and its possible impact on accounting.
\end{abstract}

Design/methodology: The review of the literature on blockchain and its importance was carried out. Also we have analyzed the Triple Entry and the so-called accounting ledger, trying to clarify some existing terminological confusion, and w e have faced what could be the future of this technology.

Findings: The review of the literature implies that Blockchain, after technical improvement and development, will involve an important transformation of the traditional accounting system, with the consequent modification of the work of accountants and auditors.

Originality/value: One of the main contributions of this study is its importance for academic literature, being one of the first to analyze the impact of Blockchain in traditional accounting.

Keywords: Blockchain, Accounting, Double entry, Triple entry

Jel Codes: M42, O30, O33

\section{To cite this article}

Pascual Pedreño, E., Gelashvili, V. \&, Pascual Nebreda, L. (2021). Blockchain and its application to accounting. Intangible Capital, 17(1), 1-16. https://doi.org/10.3926/ic.1522

\section{Introduction}

Over the last few decades, e-commerce has been dominated by banking systems acting as third parties to process electronic payments. This increases the cost associated with a transaction for both stakeholders (Nakamoto, 2008). But with the emergence of the first cryptocurrency called Bitcoin, a payment system based on 
cryptographic proof has entered into operation, removing third parties and thus being more stable and transparent (O’Leary, 2017; Agnese, 2021). This technology has been called "Blockchain" for grouping information in blocks. It has been defined as the ledger of all Bitcoin transactions, which is constantly growing as new blocks are added to record the most recent transactions. Blocks are added in chronological order, getting a copy of data which is automatically downloaded when the user joins the Bitcoin network (Swan, 2015). Other authors have referred to Blockchain as a public ledger of executed transactions (Crosby et al., 2015), an open trade ledger (Hong \& Rong, 2018), or a trustless distributed ledger that is openly available and has negligible costs of use (Deloitte, 2016).

Blockchain was initially designed to be a complementary technology to Bitcoin, but it is likely to move from a supporting tool to a technology with great impact on financial services and other industries (Fanning \& Centers, 2016). According to Yli-Huumo, Ko, Choi, Park and Smolander (2016), blockchain technology attracts attention because of its main features which are security, anonymity and data integrity, without any third party controlling the transactions. Therefore, there is more and more interest in this area of research from the perspective of technical challenges and limitations. We could say that its concept of trust lies precisely in the fact that it does not require trust. In the words of Gambetta (2000), we must have a reasonable expectation that the individuals with whom we consider trading will not take advantage of us. Even a Nobel Prize-winning economist argued more than forty years ago that lack of mutual trust affects the world's economic growth (Arrow, 1972).

In the light of all this, Blockchain is said to have the opportunity to be a transformative technology (Fanning \& Centers, 2016), regardless of Bitcoin's future. There is a fairly broad agreement that such technology will have an important impact. According to some, such impact will be transformational, on economic exchange and development. It is a technological institution that is going to be an important step in human desire to exchange value reducing uncertainty (Iansiti \& Lakhani, 2017). Therefore, it is believed that blockchain could become the fifth disruptive computing paradigm and become part of that group of computing paradigms that is composed of mainframes, PCs, the Internet and mobile/social networks (Swam, 2015).

Several previous academic studies are researching to find out the ways of applying Blockchain in multiple sectors such as banking or financial sector (Collomb \& Sok, 2016; Fanning \& Centers, 2016; Guo \& Liang, 2016), healthcare (Benchoufi \& Ravaud, 2017), accounting (O’Leary, 2017; Rückeshäuser, 2017) or auditing (Catalini \& Gans, 2016), among others. Blockchain application in accounting is one of the most debated issues (Yu, Lin \& Tang, 2018; Faccia \& Mosteanu, 2019; Tan \& Low, 2019; Fullana \& Ruiz, 2021), since it is a shared ledger. In the scarce existing accounting literature, Blockchain has been defined from Single-Entry bookkeeping (Grigg, 2005) to Triple-Entry accounting (Brandon, 2016; O’Leary, 2017). For this reason it is necessary to make a review of the previous literature in this paper.

According to $\mathrm{Yu}$ et al. (2018) the blockchain system has been applied to different industries including cryptocurrencies, corporate governance and equity finance, although it has not yet been applied to financial accounting, which is the type of accounting that is created for business external users. For this reason, if Blockchain is implemented in the area of financial accounting it can solve the problems of trust with investors, avoid communication errors or avoid the problems of asymmetric accounting information, which is one of the most common errors when summarising and interpreting the economic-financial information of the company.

Another recent theoretical study (Demirkan, Demirkan \& McKee, 2020) about the importance of Blockchain and its usefulness in accounting, he pointed out that through this system, not only can transactions be recorded, but transactions can be measured, verified and classified without the need for intermediaries. This will mean cost savings for companies in the future and will of course provide the greatest transparency for their stakeholders. In addition, implementing the Blockchain system in accounting is directly related to the trust of the information presented by companies and involves a continuous audit every time there is a transaction, which are advantages for companies (Fullana and Ruiz, 2021).

Other research on the subject also agrees that the implementation of Blockchain in accounting could have numerous advantages for companies, as well as for their internal and external users (Dai and Vasarhelyi, 2017; Bonsón \& Bednárová, 2019; Faccia and Mosteanu, 2019; Kwilinski, 2019; Cai, 2021). Taking into consideration 
the literature reviewed and the importance of the implementation of Blockchain in accounting area, the following research question has been formulated:

\section{RQ. Is it possible to implement blockchain in the accounting area? What would be the benefits for the stakeholders?}

Taking into account the research question described above, the main objectives of this study are to analyse the existing literature, to make a proposal for the application of the new technology to accounting to highlight the benefits that it would bring, as well as to clarify a certain terminological confusion that affects Double-Entry bookkeeping, Triple-Entry bookkeeping and Triple-Entry accounting, as well as the distributed ledger (Arjona, 2015; Grigg, 2005; Pascual, 2015). The reason for analysing different types of accounting is that blockchain accounting is based on Triple-Entry bookkeeping accounting (Fullana \& Ruiz, 2021). We advocate the full validity of Double-Entry bookkeeping (financial accounting system used by companies nowadays), maintaining that the so-called Triple-Entry bookkeeping equals verified Double-Entry bookkeeping (Cai, 2021). Another blockchain-related concept is Distributed Ledger Technology (DLT). As Blockchain and DLT are digitised and decentralised record books, it is often confusing as to what each of them refers to (Natarajan, Krause \& Gradstein, 2017; Arslanian \& Fischer, 2019). Literature review shown that Blockchain is a type of DLT with particular features, but not all DLTs are Blockchain. A DLT is simply a decentralized database that is managed by various participants, and we fell that by its broad and wide purpose, It would better adapt than Blockchain to the subject matter of the study, accounting.

In order to achieve the objectives set out in this study, a review of the literature on the implementation of blockchain in accounting field will be carried out. As there are no cases of such implementation at the moment, it is not possible to use different research methodologies (such as case study; research models based on data, etc) other than literature review.

This research study contributes to the academic literature on Blockchain in general. In addition to this, the literature review has show the scarce academic studies on the importance of the blockchain system in the area of accounting. Therefore, this manuscript would be of interest to the academic literature in order to develop empirical studies to prove in a practical way the numerous advantages that the implementation of the blockchain system brings to the company. We state that a change in the accounting system is coming, so academic accounting research may go hand in hand with programmers and technicians in the study of current and future uses of Blockchain in companies. It will require a continuous dialogue between accountancy, to which we belong, and technology, as it will forever change our relationship with the digital world.

This paper is split into the following sections. Section 2 examines Blockchain's background, and the evolution from Single-Entry bookkeeping to Triple-Entry bookkeeping, along with the review of the existing literature. Section 3 deals with the difference between the general ledger and the distributed general ledger. Section 4 contains the discussion, provides concluding remarks and comments on future lines of research and bibliographic references.

\section{Blockchain and Triple-Entry}

Financial frauds have been, are and continue to be crimes of intelligence that negatively affect investors, society, damage the company's reputation and deteriorate the economic and financial situation of the country in which they operate. Prominent companies such as Enron, WorldCom, Pescanova or GOWEX, among others, have committed accounting irregularities and abuses involving those responsible for financial reporting (Unerman \& O'Dwyer, 2004; Agrawal \& Chadha, 2005; Rezaee, 2005; Gurrea, 2015; Ramírez-Orellana, Martínez-Romero \& Marino-Garrido, 2017; Alfaro, 2018). It is therefore increasingly difficult for investors to rely on corporate accounting information. In Spain, the last great financial statement manipulation was committed by the company GOWEX, its founder and president being one of its top managers (Gurrea, 2015; Alfaro, 2018). The problem was that most of the revenues were false invoices, as happened with Pescanova. In addition, auditors did not verify these invoices, which meant significant negative consequences for their shareholders. If the company's earnings information had been supported by proven facts, these frauds could not have been committed. 
In the light of all this, many economic-financial reporting users wonder how to prevent tax, financial or accounting frauds. They also wonder whether annual accounts can be fully transparent, without the possibility of being altered by financial directors, auditors or accountants. The answer is yes due to the new and important technology that has appeared in the last decade, Blockchain. We can affirm that Blockchain is eminently countable, because the data are not only archived, but also dynamically settled and ordered. They also can be visualized and endowed with economic content.

Blockchain technology was first outlined in 2008 by the mysterious author(s), "Shatoshi Nakamoto", in his white paper titled: "Bitcoin: A Peer-to-Peer Electronic Cash System". To this end, the author used underlying technologies that already existed before, such as digital time-stamping (Haber \& Stornetta, 1991), or the Hascash proof-of-work (Back, 2002). He combined them with a protocol that encouraged participation. In essence, Blockchain was created as a technology associated with the Bitcoin digital currency (Yli-Huumo et al., 2016; O Leary, 2017). Its definition states that it is an open and distributed ledger system, where users can record transactions without third parties (Iansiti \& Lakhani, 2017; Budish, 2018). It lowers operational costs (Catalini \& Gans, 2016; Iansiti \& Lakhani, 2017), and once a transaction is done, the record is visible to all users. This implies that transactions are transparent and cannot be altered or manipulated later (Dolader. Bel \& Muñoz, 2017).

According to Khanh (2016), there are several advantages and drawbacks associated with the implementation of Blockchain. Its most outstanding advantages include an increase in the efficiency of transactions in the stock market, a cheaper financial service; the automatic recording of transactions makes it possible to avoid manipulation of data, better protection of transactions than that carried out by financial institutions and regulatory bodies. It saves time and eases the follow-up process of trade agreements. With regard to drawbacks, a public Blockchain system, such as the one used by Bitcoin, processes very few transactions per second. This limitation is overcome by another type of Blockchain, with higher transaction rates per second, such as Ethereum, Quorum for a semi-permissioned network, or Hyperledger for a private network. The correct use of such technology can limit the competitiveness among financial institutions, as through it they can improve their own operational system and share the application among themselves (of course only for financial institutions that are Blockchain clients). However, the lack of concrete legislation and regulation of cryptocurrencies can have a negative impact on the application. Finally, it would mean time and effort on research and implementation for the banking industry. In short, it may be said that Blockchain can provide robustness, security, transparency and stability to large data systems (Dolader et al., 2017) and can be a very useful tool, especially for financial companies.

However, Blockchain application is not only foreseen in the banking sector, but also in a vast array of sectors such as public, healthcare, energy, or accounting and auditing (Catalini and Gans, 2016; Mattila, Seppälä, Naucler, Stahl, Tikkanen, Bådenlid \& Seppälä, 2016; Benchoufi and Ravaud, 2017; O’Leary, 2017; Umeh, 2018). As will be shown below, in the accounting sector it is increasingly considered that its application will mean a shift from traditional Double-Entry bookkeeping to Triple-Entry bookkeeping (Rodríguez, Piñeiro \& De Llano 2014). However, at this point we may find some terminological confusion. The terms "Double-Entry bookkeeping" and "Double-Entry accounting" are mentioned. Mentions are made of "Triple Entry bookkeeping" (Arjona, 2015) and "Triple-Entry accounting" (O'Leary, 2017), and even "universal entry accounting" (Grigg, 2005). In addition, we may point out the advent of the World Wide Ledger (WWL), which is in the words of Tapscott and Tapscott (2016), "the ultimate implementation of a verifiable, auditable and searchable Blockchain accounting system, where international corporations publish all their transactions and make them available for regulators, managers and key stakeholders".

In this section, therefore, we are about to provide clarity to the profusion of accounting terms referred to, as well as to the ideas underlying them. Norms and standards dealing with Blockchain will not be a minor challenge, and the main accounting firms and organisms that issue norms can contribute their experience to this work. 


\subsection{Brief overview of Single-Entry bookkeeping}

History has kept the evidence that in the Mesopotamian era thousands of years ago, there was a rather complex accounting of goods, purchases, income, etc. In the Middle Ages, a fairly advanced accounting system was used by Italian merchants, in line with the evolution of trade. But before the advent of Double-Entry bookkeeping, bookkeepers in that period used an accounting system that is based only on an accounting entry, but provides basic financial information on assets or liabilities (Grigg, 2005). Such a method had the advantage of simplicity, but it should be borne in mind that in that accounting system it was difficult to track down and repair possible accounting errors. It should be noted that an entry can be added or deleted at any time, as it does not have Double-Entry feature which helps trace the source of origin that entry. Grigg (2005) points out that Single-Entry bookkeeping would not work for companies requiring Double-Entry.

As a matter of fact, this is a system that is very difficult to examine for accountability. Today such a system would cause many problems for external and internal accounting users, as companies would not present an Income Statement. In particular, it would not be possible to see changes in net equity. Manipulation would be as simple as removing a line in the ledger, and that money would cease to exist. Therefore, there would be no way to check, audit, reconcile items, or to reach an agreement on profits or losses. In view of the above, it is easy to suppose the great advance that Double-Entry bookkeeping entailed.

\subsection{Double-Entry bookkeeping}

The work done by Grigg (2005) has shown that Double-Entry bookkeeping could have been created to meet the demands of the newly expanding enterprises of the states, such as Venice. Indeed, Double-Entry bookkeeping revolutionized financial accounting field during the Renaissance period. The first to refer to the Double-Entry bookkeeping system was Benedetto Cotruglio Raugeo, who wrote the manuscript Della Mercatura et del Mercante perfetto in 1458 (thus 36 years before the publication of Luca Pacioli's work), although it was published in 1573. However, a Franciscan friar Luca Pacioli (1445-1517) is recognized as the father of accounting thanks to his work "Summa Arithmetica, Geometria, Proportioni et Proportionalita", published in 1494. He was the first treatise writer to take advantage of the invention of printing, since Gutenberg printed his Bible in 1450. In his book, Pacioli sets down the Double-Entry bookkeeping system in force until our days: the "Alla Veneziana" system, based on Debit and Credit, and that quickly became the one used by the Italian merchants.

Currently, Double-Entry bookkeeping is the only accounting method, being this the final link in the development of different techniques dedicated to meeting economic and financial record needs (Hernández, 2006). In this sense, it is a comprehensive set of records that give a global and detailed vision of the company or production unit, so that each operation carried out is noted. It opposes the simple entry method in which only some of these transactions are recorded, the information provided being partial. In addition, it should be noted that Luca Pacioli warned that it was not possible to omit economic and financial information from the accounting records and that a comprehensive record of transactions was necessary for successful business operations (Scoll, 2014).

There are two factors in all operations carried out by a company: an exchange of goods or services and money. Therefore, in any transaction there will be on the one hand, the origin or resource of the operation, and on the other, the use or application of that resource. That exchange is precisely the foundation of the so-called DoubleEntry system: for every financial transaction recorded in the book, its counterpart may be reflected (Pascual, 2015).

Modern accounting is therefore based on a Double-Entry system (Sangster \& Scataglinibelghitar, 2010). But we cannot speak of an unfailing system, because there is not really any connection between companies' ledgers, so one of them, or both, can manipulate the data.

With the development of companies and their activities, they were expected to share the data with external users, like as potential investors, suppliers, creditors or the state itself. But these external agents are wary of accounting, as there is no guarantee that its content is real, which makes the presence of the auditors necessary. Auditors 
should turn to suppliers, customers and banks to verify that the data reflected in the accounts are true. Consider the time and work required for all of this, as well as the cost. For example in the Pescanova case up to $90 \%$ of its false invoices were issued by African companies and not audited due to the high costs of travelling in order to contrast the data. It is not surprising that the next step in the accounting evolution comes to alleviate this problem. This is not to say that Double-Entry bookkeeping is obsolete. On the contrary, we are aware of its transcendence and its full validity. Users must reflect the actual data.

\subsection{Triple-Entry bookkeeping}

As we have pointed out before, for more than six centuries our modern accounting system has been founded on Double-Entry method. This basic pillar has not only experienced the recent economic and financial crisis, but also various reforms, as well as the emergence and development of new technologies. From the current paradigm we should point out the great importance of entity's cash flow, as reflected in the shift in bookkeeping from Cash Flows Statement (CFS) to Annual Account. It reflects how an entity's cash (cash and demand deposits) and cash equivalents vary over time. "Cash equivalents" means a type of current asset that is highly liquid and can be converted into cash very easily. Such is their importance that Lev, Siyi and Sugiannis (2010) stated in a comprehensive empirical study that cash flows predict corporate performance better than accounting profit itself.

CFS aims at collecting all transactions related to the company's cash flow. Therefore, it provides information on the origin and use of current assets, in particular, cash and cash equivalents movements classified by activities and indicating changes in net assets in the accounting year (Pascual, 2017). It highlights the changes in cash produced by the inflows and outflows from operating, investing and financing activities during a particular period. CFS is useful since it provides the economic entity and the person in charge of financial reporting with a basis for assessing an entity's ability to generate cash and its equivalents and the needs to use it in the administration and top management (Rivero, 2015).

However, given that there are many methodologies developed on the basis of the standards and norms included in the General Accounting Plan, we do not currently have a general framework that unifies the preparation of Cash Flow Statement,

Having said that, Triple-Entry Method or Triangular Accounting consists of supporting the recording of cash flows and adding a record to each entry. Apart from the debit and credit entries, a third item will be recorded for the flows, giving rise to three items instead of two. In the words of Arjona (2012) it is not intended to be a new accounting system or a different form of accounting, but rather a logical evolution, an addition to the current accounting. Ibáñez (2018) adds that cash flow included in the journal entries reflects changes in cash, which do not necessarily correspond to cash movements, and may be investment or financing flows. This provides triple information and the preparation of CFS, which supposes an improvement of the dual accounting.

Thus, Triple-Entry bookkeeping is in accord with Double-Entry bookkeeping as a systemic improvement, as if it were the development of the third accounting dimension, which makes it possible to codify a third, apart from the two dimensions that we have been using for more than six centuries (Debit and Credit): the movement of flow (Arjona, 2015).

As far as we are concerned, we should first point out that such a proposal for accounting has nothing to do with Triple-Entry bookkeeping associated with Blockchain, which will be described below.

On the other hand, we must welcome the emergence of such a proposal, as any contribution to the progress of accounting. However, we understand that it will not be applicable in practice. Even if those obliged to keep accounts were prepared to make the great effort to break with the traditional Double-Entry, they would hardly opt for a much more complex method. In fact, the current trend is towards increasing simplicity in accounting. Spatt (2012) himself affirms that complexity of accounting rules leads to complexity in the very structure or entity they should protect, becoming a vicious feedback circle. Lev and Gu (2017) also advocate a reduction in 
the complexity of accounting. And this trend is currently followed for accounting principles generally accepted in the US and the International Financial Reporting Standards in Europe.

\subsection{Triple-Entry bookkeeping associated with Blockchain}

\subsubsection{Triple-Entry precursors}

It is remarkable that the first reference to the Triple-Entry bookkeeping was found in 1986 (Ijiri, 1986). Although his work is not related to cryptography or Blockchain, it is interesting to refer to it. According to this author, current accounting system is not an absolute system, but it is of course possible to extend it to Triple-Entry bookkeeping. The main difference that can be seen between Double-Entry bookkeeping and Triple-Entry bookkeeping accounting is that this last one has three basic financial statements proposed: wealth statement, momentum statement, and force statement.

Analysed separately, the wealth statement presents the wealth and income of the company, where wealth is calculated as assets minus liabilities and income is calculated as revenues minus expenses. In case of momentum statement it can be seen that the author argues as an annual account that gives the information about the income. That annual account has two columns and the result of these two columns calculates the net result of the company or the wealth achieved during the accounting period. Finally, the force statement is presented with three columns and all transactions in this statement have Single-Entry transactions. The three columns present the force, impulse, and action accounts and all of them are made based on the Triple-Entry bookkeeping.

We find the next step in Triple-Entry bookkeeping in Grigg (2005). Although in the case of Ijiri (1986) we affirm that his work is not related to crypto-currencies and Blockchain, this is far from being the case for Grigg. In spite of being prior in time to the emergence of both institutions, we understand that his work had an important influence on their configuration. Chon (2017) has made a deep analysis in an attempt to identify the true identity of unknown Satoshi Nakamoto, concluding that they are the two cited authors, Grigg and Szabo. Grigg then defends that the existence of the digitally signed receipt, which authorizes the transaction, represents an important defiance to Double-Entry bookkeeping, at least at the beginning for the conceptual part. In addition to that, the digital signature confers a high probative force to the receipt, because in terms of evidence and due to the technical qualities of its signature, it is more powerful than Double-Entry records. The possible problem of the absence of a receipt is solved by sharing the records, which will allow each of the agents to have a copy. In addition, it should be noted that there are three accounting entries for each of the transactions. In these entries the natural roles of a transaction are divided into three parts that would be three by three entries. He adds that "our term of Triple-Entry bookkeeping recommends an advance in accounting, rather than a revolution".

In short, Grigg (2005) analysed the possibility of using secure transactions with digital receipts that would be cryptographically protected. On this basis it would be possible to store different transactions made by various parties and to check whether the stored data has been deleted or changed. It gives us some idea of his influence on subsequent researchers that led to the emergence of Bitcoin and Blockchain. It should be noted that with the implementation of Blockchain technology, accounting processes could be cheaper, more automated and of course more reliable for companies.

\subsubsection{Blockchain and Triple-Entry bookkeeping}

We have already talked about the close linkage between accounting and Blockchain in the introduction, and defined it as a general ledger. There is a coherent description of the possibility for companies to keep an accounting based on such technology, which offers complete transparency and eliminates the need for trust in any intermediary. At present, accounting is obliged to trust in the integrity of bookkeepers and auditors who in turn are susceptible to corrupt behavior.

Indeed, perhaps the time has come to break with our way of understanding accounting. This does not imply that the pillars supporting the current paradigm must be eliminated, but we cannot avoid the fact that the emergence 
of Blockchain technology provides us with the necessary tools to evolve in bookkeeping. As Libby (2017) states, it will allow us to overcome the limitations of traditional financial reporting systems.

Blockchain has been defined as a decentralized and distributed database that allows information to be consulted, but not copied or altered. Created to articulate Bitcoin cryptocurrency transactions and based on a network nodes or computers that no one controls (although we can say that today, whoever controls the maximum number of validating nodes can control the direction in which Blockchain evolves), this disruptive technology is considered to be secure thanks to its novel cryptographic system (Yu et al., 2018). This has led Lemieux (2016) to affirm that a record is reliable if it accurately represents the facts to which it attests, and authentic if it has not been tempered with or corrupted (i.e., it is the record that it claims to be). Bear in mind that it moves data from a centralized database to a distributed ledger that runs on many nodes (Walch, 2015).

Triple-Entry bookkeeping is a simple idea. When carrying out the transaction, a receipt is signed through the digital signatures of the users, so we are assuming that throughout Blockchain each user has a unique and nontransferable digital signature. Thus, we can affirm that this is an improvement on the current accounting system, as the accounting entries made by companies are visible to the parties involved and are cryptographically sealed by a "third entry", made by the network itself. The final receipt has the digital signatures of all the parties, and becomes a very valuable proof of transaction: that is the "third entry". In the words of Ibáñez (2018), triple bookkeeping means direct connection between two operators (P2P) and the proof record given by the network of nodes. Operations are automatically reconciled and recorded, without the involvement of third parties, so that in decentralized registries everyone becomes simultaneously aware of the operations. The consequence is that internal accountants, auditors or external experts are not required to issue documentary supports (delivery notes, invoices), and verify the concordance between supports and accounting entries system.

Let us consider the following example. During a transaction, in the traditional system subject A records in his or her Journal that he has sold a given quantity of goods; subject B notes a purchase in his or her Journal. However, if we use Blockchain, both parties will digitally sign a receipt, in which they confirm that the goods have been delivered in exchange for the stipulated price. The issued receipts A and B become an encrypted and unmodifiable proof of the transaction through Blockchain. Since the entries are distributed and cryptographically sealed, their manipulation seems practically impossible. See a complete study by Preneel (2010) on the evolution of cryptographic functions.

Similarly, González (2018) states that if transactions are recorded in the ledger of both parties, a third party, that is the chain of blocks, will emerge in the future, generating a Triple-Entry system that will make audit routines simpler and more automated. Triangular Accounting, cryptography and Blockchain are a way of agreeing on an objective reality: they are two parts outlining a version of past events thanks to an exportable system, individually verifiable and more manageable by computers.

The mere adoption by companies of the Triple-Entry bookkeeping method could immediately provide two noteworthy benefits. First, this would extraordinarily facilitate the work of auditors, since they would be able to verify the majority of the data contained in the financial statements easily and quickly, resulting in significant economic and time savings. This would help them to focus their efforts on the parts that have the highest control risk, e.g. internal control. And secondly, the financial statements prepared by companies on an annual basis and the information presented in them would be more secure and reliable. Keep in mind that transactions carried out could not be falsified, since they would require the encrypted signature of the counterpart in order to be accepted as valid.

In the light of all this, we can say that the advantages of the Triple-Entry bookkeeping system are several; among them one could distinguish reconciliation, transparency, trust and ease of auditing. Such a system will allow accountants or persons involved in it to reconcile the account balance, transaction and reporting process so that companies can have full confidence in their own Journal books. Triple-Entry bookkeeping reduces such current risks by maintaining an unbiased record. 
On the other hand, it is feared that the adoption of Blockchain by the business world will increase the bill between large and small companies. However, we understand that the use of the above-mentioned Triple-Entry system would strengthen smaller companies and could favor their growth opportunities, as it would offer them a very economical way of demonstrating business activity to external stakeholders.

Benefits that could be produced in each company's internal accounting must also be taken into account. Since entries are made directly on the blockchain, recorded transactions will be more reliable as they can be easily verified and will be identical for each party linked to the transaction. It may be say that it has been initially used for transactions between companies belonging to the same group. However, its natural evolution should be towards transactions carried out between those outside the group, creating what could be called a common accounting book.

In this sense, Ibáñez (2018) reports that in automated Triple-Entry bookkeeping, accounting entries of three groups of subjects are synchronized: one part of the transaction, the second part and the nodal network, which simultaneously records the same data on the blockchain. This is very important, as it permits corporate savings on the numerous conciliation costs and internal audit that might be incurred by legal contract to carry out the ordinary activity. It also makes it possible to avoid those associated with external advertising and evidence of transactions.

In the DLT environment, operations are automatically reconciled and recorded, without the involvement of third parties, so in the decentralized registers everyone becomes aware of the operations simultaneously. For this reason, there is no need to have an internal company accountant, or an external auditor or expert to issue documentary supports to record (delivery notes, invoices) and verify the concordance between the supports and the accounting entries system. In addition, the identity between accounting entries made by the stakeholders is guaranteed. Therefore, it is not necessary to issue proof of receipt of the parties' consideration for final mutual evaluation and proof of final knowledge of the reality of the assets exchange. This is an important advantage, since the validity of accounting entries is no longer guaranteed by mutual control between parties, or their internal or external auditors, but by the information contained in the network itself.

For our part, we understand that the aforementioned Triple-Entry bookkeeping expression is graphic and expressive. The new third entry corresponds to Blockchain and consists of a proof that a transaction occurred between two interested parties, and of course it will be more reliable than a transaction made in the DoubleEntry system. However, we understand that it would be equally correct to refer to a verified (or qualified) Double-Entry bookkeeping in which the Double-Entry corresponds to both parties, and the verification of the transaction to Blockchain.

Either name, it seems clear to us the superiority of the DLT environment over conventional accounting. On the one hand, by the immediacy of authorized nodes access to the content of accounting information dumped in distributed records. And on the other hand, by the use of Blockchain-based smart contracts as programs that trigger transaction orders, when these have economic content requiring to be legally recorded (Tan \& Low, 2019). The execution of the program itself is recorded in the Blockchain, serving as support, receipt and proof of the exchange simultaneously in all the computers of the involved parties and of all third parties enabled to share information in the network.

One example is Ibáñez's proposal (2018): if a delivery order for a purchased product is cryptographically signed, the buyer records the cryptographically received product. A payment by virtual currency is automatically sent to the seller's account, and the transaction is automatically recorded with its payment and delivery phases by the counterpart of its consideration. And the intelligent contract can ensure not only the recording of the transaction support (invoice, delivery note, virtual contract), but also the accounting record itself (mandatory books). 


\section{General ledger versus distributed general ledger}

As stated in the Double-Entry study, Benedetto Cotruglio Raugeo wrote the manuscript Della Mercatura et del Mercante perfetto in 1458, published in 1573. In his chapter on accounting, he establishes the use of three books: Mayor (Ledger), Giornale (Journal) and Memoriale (Memorandum). He also refers to the transfer of entries from Journal to Ledger, as well as the need to close the accounts and write down the balance on the last page of the Ledger when it is full.

Article 35 of the Spanish Commercial Code requires all traders to keep orderly a Journal, a Book of Inventories and an Annual Accounts book, so the General Ledger is not mandatory. Although it is a widely used accounting book, it is quite normal that it is not compulsory, since it contains the same information as the Journal but in a different format. Pascual (2017) highlights its importance as a subsidiary to the compulsory books. As the Journal is available in the Excel spreadsheet, the Ledger is just a filter of the Journal. We even dare to say that the Journal is a kind of Big Data, because it stores all the accounting data, which will allow us to produce not only the General Ledger, but also the Financial Statements. In other words, the Journal Book contains a vast amount of accumulated information on which certain processes will have to be carried out to obtain knowledge (Demirkan et al., 2020).

International Financial Reporting Standards refer to the presentation of Financial Statements, but not to accounting books, as is the case with US GAAP.

We have considered of interest to make this brief introduction to the General Ledger, widely known, to distinguish it from the widespread use of General Ledger term in the Blockchain, as a translation of the English term ledger. Even when terms coincide, the meaning is different. Note that in Blockchain the account concept does not relate to its transaction, which collects the data of a movement that may be equity, but is not associated with assets and liabilities record. Although they do not coincide, the term is closer to the Journal book, since both can collect data on Equity movements. But they are different, since an entry in the Journal has a mere accounting relevance, while entries in Blockchain aim at incorporating rights and protecting digital assets investments.

One of the names given to Blockchain technology is Distributed Ledger Technology (DLT). Although it is the same technology, it is often used in the field of private development and is not related to Bitcoin as cryptocurrency. In other words, Blockchain is a type of DLT with particular characteristics, but not all DLTs are Blockchain. A DLT is simply a decentralized database that is managed by several, it is an operation database spread across several nodes, rather than stored in a centralized database. Blockchain is a type of DLT, a peer-topeer network (participants are all equal, there is no intermediation) to exchange values that relies on the digital signature and the distributed ledgers, with its unique arrangement in chain of blocks. Once this distinction has been made, we consider that, due to its broad and wide purpose, DLT would adapt better than Blockchain to accounting, the subject matter of our study.

As mentioned earlier, English literature uses the word ledger to refer to the book in which transactions are recorded, while the Spanish word is general ledgers or simply, ledgers. "Decentralized ledger" suggests an analogous situation in which each page of a company's ledger is indefinitely opened to customers and suppliers who can verify or modify incorrect or insufficient data. As new transactions are carried out, the following page will be shown, and so on (González, 2018).

However, another term that can be analysed and linked to blockchain accounting is the World Wide Ledger (WWL). Although it does not have a strict definition, it is frequently used in connection with such technology. According to Tapscott and Tapscott (2016), the WWL can be understood as one of the essential parts of the ultimate implementation of Blockchain accounting that allows for more reliable, auditable and easy to find/identify information in the system for regulators, managers and stakeholders. It is therefore believed that WWL will streamline the work of accounting information stakeholders. Deloitte (2016) indicates that it should be kept in mind that, although Triple-Entry bookkeeping is currently used primarily in connection with Blockchain. Therefore, it can only state that these transactions are time-stamped. For this reason, the advantages 
mentioned above can only be seen in the next stage of development of blockchain accounting, as is the case with World Ledger.

In short, the underlying idea is the need for a massive adoption of accounting. The adoption of such accounting practices is mandatory for all counterparts. In this sense, González (2018) indicates that certainty and transparency on accounting data opens up new possibilities for cooperative compliance, at national and international levels (Kwilinski, 2019).

Blockchain ledger aims at updating and storing all transactions occurring within and outside the company with various counterparties. But that is going to be done only in the case that if the transaction input is the transaction itself, that means that all transactions must be done in the form of "token" transfers (understood as a digital representation of the company's FIAT money) within the blockchain, this is only possible if all parties involved in the transaction have implemented the blockchain system in advance. Despite these advantages, it should be noted that in isolation, the system can write and store transactions purely within the company and can sometimes be difficult to find.

\section{Conclusions}

Without prejudice to the multiple utilities that Blockchain has, we can affirm that it is an eminently accounting technology, since data are not only archived, but also dynamically settled and ordered, they can be visualized and endowed with economic content. Its application to accounting will follow a trajectory similar to other technologies, which have evolved from their beginning until to be adopted.

We have argued that even when there is a tendency to equate Blockchain with Distributed Ledger Technology (DLT), Blockchain is a type of DLT with special features, but not all DLTs are Blockchain. A DLT is simply a decentralized database that is managed by various participants, and we feel that, because of its broad and wide purpose, it would better adapt than Blockchain to accounting, the subject matter of our study.

Similarly, we have shown that Blockchain used by the cryptocurrency Bitcoin is not the most suitable application to accounting. There are other types, such as Quorum, which permits private transactions and the creation of a semi-permissioned network, in which it is necessary to request access in order to participate, but with free access to public data consumption. In addition, by replacing the mining with another system executing actions and transactions, we achieve greater agility.

In the revised literature we have found some terminological confusion that we have sought to clarify, in what we consider to be one of the contributions of this study. We are referring to the confusion between Blockchain and DLT, mentioned above. Also, the concepts of double and Triple Entry were revised, as well as the concepts of Double-Entry bookkeeping and Triple-Entry bookkeeping. And, especially the equating of Blockchain with the ledger. All of this is discussed below.

All of the above is one of the factors that have led us to advocate the need for academic accounting research to go hand in hand with programmers and technicians in the study of current and future uses of Blockchain in companies. It would be desirable a continuous dialogue between accountancy, to which we belong, and technology.

We advocate the need for retraining for the accountant that helps understand and know how to use technology, collaborating in the development of Blockchain solutions. His or her advisory function is essential for companies to adapt to new technology (avoiding the invoice between small and large companies), facing accounting, not from the perspective of data and transaction, but from the perspective of the value it can generate in the organization. In our opinion, accountants will cease to be mere bookkeepers and move closer to financial advisors in their role.

With regard to the intended transition from Double-Entry to Triple-Entry bookkeeping, we stand for the full validity of the Double-Entry bookkeeping. Thus, we have referred to Triple-Entry bookkeeping (not to be confused with Triple-Entry accounting) consisting of recording, in addition to debit and credit entries, a third 
entry for cash flows, giving rise to three entries instead of two. In this respect, we have concluded that it will not be applicable in practice. Even if those obliged to keep accounts were willing to make the great effort to break with the traditional Double-Entry, it would be difficult for them to opt for a much more complex accounting method, when the tendency is to simplify it.

Regarding the extended Triple-Entry accounting concept, the new third entry corresponds to Blockchain and it is the receipt that proves the transaction between the parties, which is more secure than the receipts held by each stakeholder through the Double-Entry system. However, in our opinion it would be equally correct to refer to a verified (or qualified) Double-Entry accounting in which the Double-Entry corresponds to both parties, and the verification of the transaction to Blockchain.

Blockchain is defined as a General Ledger from the English term ledger, and this has led to erroneously equate it with the ledger, which is a subsidiary accounting book in Spain. Indeed, in Blockchain the concept of account does not relate to its transaction. It collects the data of a movement that may be equity, but is not associated with assets and liabilities record. It is closer to the Journal, since both can collect data on Equity movements. But they are different, since the entry in the Journal has a mere accounting relevance, while entries in Blockchain aim at incorporating rights and protecting investments in digital assets.

We have referred to the immeasurable benefits produced by the application of this technology in accounting: it is not necessary to have an internal accountant of the company, an external auditor or expert to issue documentary supports in order to record the operation and to verify the concordance between the supports and the system of accounting entries. In addition, the identity between accounting entries made by stakeholders is guaranteed. Thus, it is not necessary to issue proof of receipt of the parties' consideration for final mutual verification of the asset exchange reality. Therefore, the validity of accounting entries is no longer guaranteed by mutual control between parties, or their internal or external auditors (Schmitz \& Leoni, 2019), but by the information contained in the network itself. Accounting information may not be modified, which will act as a mechanism to minimize conflicts and will mean an important increase in trust level for society, investors and stakeholders. Therefore, we believe that this study contributed to forecasting the early arrival of Blockchain in accounting, based on transparency, which would lead to trust in the authenticity of records. To this should be added the enjoyment of accounting information in real time, as well as the reduction of costs, not forgetting the improvement of analysis techniques and the fight against fraud and corruption. Such advantages would not only apply to large companies, but to all companies, irrespective of their size.

Among the limitations, it is worth noting that research on the topic is limited, as well as the lack of detailed mechanisms on what the practical application of blockchain on accounting and auditing would look like. This is because we are at an early stage, so more concrete and research is still needed on the technological issues, and a wider dissemination of all the possibilities that the use of blockchain in accounting and auditing would offer. Having done so, we believe that consensus between government, regulators, accountants and auditors would be paramount.

As for future lines of research, we look forward with great anticipation to the beginning of the application of blockchain in accounting and auditing in organisations, carrying out a case study and testing the improvements achieved with its use. Our intention is to focus the study on how the disruption caused by the application of blockchain would affect the work carried out by accountants and auditors. It would be a quantitative study based on a real case.

We follow with great interest the rapid progress made by the Big Four. Deloitte has already launched a blockchain-based software platform, called Rubix, which can already be used by its clients. KPMG has developed its digital ledger services in collaboration with Microsoft. Ernst \& Young has launched distributed ledgers, a project called Libra. And PWC is working on applying blockchain to the energy sector.

Nor can we forget the European Blockchain Partnership, an organisation created in 2018, which unites all EU Member States at a political level, which are committed to exploiting the possibilities of the blockchain, for which it is building a European infrastructure of services for this purpose, the EBSI. 
In this way, blockchain technology will continue to advance, undergoing a process of improvement and technical change until it reaches maturity (Fullana \& Ruiz, 2021). Undoubtedly, it will continue to connect with other technologies, such as artificial intelligence or cloud services, as well as promoting research in those areas in which it can generate greater benefits, among which, bookkeeping.

\section{Acknowledgments}

The authors are very much in debted to Prof. María del Mar Camacho-Miñano who has provided valuable comments to improve this paper.

\section{Declaration of Conflicting Interests}

The authors declared no potential conflicts of interest with respect to the research, authorship, and/or publication of this article.

\section{Funding}

The authors received no financial support for the research, authorship, and/or publication of this article.

\section{References}

Agnese, P. (2021). On blockchains, cryptos, and media of exchange. Not there (yet). International Journal of Intellectual Property Management, 11(1), 81-94. https://doi.org/10.1504/IJIPM.2021.113359

Agrawal, A, \& Chadha, S. (2005). Corporate governance and accounting scandals. TheJournal of Law and Economics, 48(2), 371-406. https://doi.org/10.1086/430808

Alfaro, M.F. (2018). El papel del auditor en el fraude contable. Derecho en Sociedad, 11, 1-29.

Arjona B.A. (2012). La contabilidad triangular o de partida triple. Alicante, España: El Club Universitario.

Arjona B.A. (2015). Planteamiento de la Contabilidad Triangular o de Partida Triple. XVII Congreso Internacional AECA. Congreso llevado a cabo en Braganç, Portugal. Disponible en: http://www.aeca1.org/pub/on line/comunicaciones xviicongresoaeca/cd/12a.pdf

Arrow, K.J. (1972). Gifts and Exchanges. Pbilosophy \& Public Affairs, 1, 343-362.

Arslanian, H., \& Fischer, F. (2019). Blockchain as an enabling technology. In The Future of Finance (pp. 113-121). Palgrave Macmillan, Cham. https://doi.org/10.1007/978-3-030-14533-0_10

Back, A.(2002). Hashcash - A Denial of Service Counter-Measure. Disponible en: http://www.hashcash.org/papers/hashcash.pdf

Benchoufi, M, \& Ravaud, P. (2017). Blockchain technology for improving clinical research quality. Trials, 18(1), 335. https://doi.org/10.1186/s13063-017-2035-z

Bonsón, E., \& Bednárová, M. (2019). Blockchain and its implications for accounting and auditing. Meditari Accountancy Research, 27(5), 725-740. https://doi.org/10.1108/MEDAR-11-2018-0406

Brandon, D. (2016). The blockchain: The future of business information systems. International Journal of the Academic Business World, 10(2), 33-40.

Budish, E. (2018). The Economic Limits of Bitcoin and the Blockchain. National Bureau of Economic Research. New Working Paper Series No. 24. University of Chicago. https://doi.org/10.3386/w24717

Cai, C.W. (2021). Triple-entryaccounting with blockchain: How far have we come?. Accounting \& Finance, 61(1), 71-93. https://doi.org/10.1111/acfi.12556

Catalini, C, \& Gans, J.S. (2016). Some simple economics of the blockchain. NBER working paper series (No. w22952). National Bureau of Economic Research, Cambridge. https://doi.org/10.3386/w22952

Collomb, A., \& Sok, K. (2016). Blockchain/Distributed Ledger Technology (DLT): What Impact on the Financial Sector? DigiWorld Economic Journal, 103(3), 93-111. 
Chon, M. (2017). Stylometric Analysis: Satoshi Nakamoto, Towards Data Science. Disponible en: https://towardsdatascience.com/stylometric-analysis-satoshi-nakamoto-294926cdf995

Dai, J., \& Vasarhelyi, M.A. (2017). Toward blockchain-based accounting and assurance. Journal of Information Systems, 31(3), 5-21. https://doi.org/10.2308/isys-51804

Deloitte (2016). Blockchain Application in Banking. Disponible en: https://www2.deloitte.com/content/dam/Deloitte/ch/Documents/innovation/ch-en-innovation-deloitte-blockchainapp-in-banking.pdf

Demirkan, S., Demirkan, I., \& McKee, A. (2020). Blockchain technology in the future of business cyber security and accounting. Journal of Management Analytics, 7(2), 189-208.

Dolader, C.R., Bel, J.R, \& Muñoz, J.T. (2017). La blockchain: fundamentos, aplicaciones y relación con otras tecnologías disruptivas. Economía industrial, (405), 33-40.

Faccia, A., \& Mosteanu, N.R. (2019). Accounting and blockchain technology: From double-entry to triple-entry. The Business \& Management Review, 10(2), 108-116.

Fanning, K, \& Centers, D.P. (2016). Blockchain and its coming impact on financial services. Journal of Corporate Accounting \& Finance, 27(5), 53-57. https://doi.org/10.1002/jcaf.22179

Fullana, O., \& Ruiz, J. (2021). Accounting information systems in the blockchain era. International Journal of Intellectual Property Management, 11(1), 63-80. https://doi.org/10.1504/IJIPM.2021.113357

Gambetta, D. (2000). Can We Trust Trust?. In Gambetta, D. eds., Trust: Making and Breaking Cooperative Relations (213-237). Oxford: Blackwell.

González, U.G.F. (2018). La fiscalidad en el mundo Blockchain. Estudios financieros. Revista de contabilidady tributación: Comentarios, casos prácticos, 425, 5-36.

Grigg, I. (2005). Triple entry accounting. Systemics Inc., 1-10.

Gurrea, A.M. (2015). Alternative investment markets under criticism: Reasons to be worried? Lessons from Gowex. Journal of Financial Regulation, 1(1), 164-168. https://doi.org/10.1093/jfr/fju008

Guo, Y, \& Liang, C. (2016). Blockchain application and outlook in the banking industry. Financial Innovation, 2(24), 1-12. https://doi.org/10.1186/s40854-016-0034-9

Haber, S, \& Stornetta, S. (1991). How to Time-Stamp a Digital Document. Journal of Cryptology, 3, 99-111. https://doi.org/10.1007/BF00196791

Hernández, E.E. (2006). Reflexiones sobre la naturaleza y los orígenes de la contabilidad por partida doble. Pecunia, 1, 93-124. https://doi.org/10.18002/pec.v0i1.743

Hong, S, \& Rong, S.C. (2018). Developing a Blockchain based Accounting and Tax Information in the 4th Industrial Revolution. Journal of the Korea Convergence Society, 9(3), 45-51.

Iansiti, M, \& Lakhani, K.R. (2017). The truth about blockchain. Harvard Business Review, 95(1), 118-127.

Ibáñez, J.W. (2018), Blockchain: Primeras cuestiones en el ordenamiento español. Dykinson, 61, 1-192.

Ijiri, Y. (1986). A framework for triple-entry bookkeeping. Accounting Review, 61(4), 745-759.

Khanh, N.Q. (2016). In 2016 3rd International conference on green technology and sustainable development (GTSD) (IEEE, 2016), pp. 51-54

Kwilinski, A. (2019). Implementation of blockchain technology in accounting sphere. Academy of Accounting and Financial Studies Journal, 23, 1-6.

Lemieux, V.L. (2016). Trusting Records: Is Blockchain Technology the Answer?. Records Management Journal, 26, 110-139. https://doi.org/10.1108/RMJ-12-2015-0042 
Lev, B., Siyi, L, \& Sugiannis, T. (2010). The Usefulness of Accounting Estimates for Predicting Cash Flows and Earning. Review of Accounting Studies, 15, 779-807. https://doi.org/10.1007/s11142-009-9107-6

Lev, B, \& Gu, F. (2017). El final de la contabilidad. Barcelona: Editorial Profit.

Mattila, J., Seppälä, T., Naucler, C., Stahl, R., Tikkanen, M., Bådenlid, A, \& Seppälä, J. (2016). Industrial blockchain platforms: An exercise in use case development in the energy industry. Working paper No. 43. The Research Institute of the Finnish Economy.

Nakamoto, S. (2008). Bitcoin: A peer-to-peer electronic cash system. Disponible en: https://bitcoin.org/bitcoin.pdf

Natarajan, H., Krause, S., \& Gradstein, H. (2017). Distributed ledger technology and blockchain. World Bank. https://doi.org/10.1596/29053

O'Leary, D.E. (2017). Configuring blockchain architectures for transaction information in blockchain consortiums: The case of accounting and supply chain systems. Intelligent Systems in Accounting, Finance and Management, 24(4), 138-147. https://doi.org/10.1002/isaf.1417

Pascual, E. (2015). Contabilidad: iniciación práctica (5ª edición). Valladolid: Thomson Reuters.

Pascual, E. (2017). Obligaciones contables y fiscales del empresario. Pamplona: Thomson Reuters.

Preneel, B. (2010). The first 30 years of cryptographic hash functions and the NIST SHA-3 competition. In Cryptographers' track at the RS A conference, 1-14. Springer, Berlin, Heidelberg. https://doi.org/10.1007/978-3-64211925-5_1

Ramírez-Orellana, A., Martínez-Romero, M.J, \& Marino-Garrido, T. (2017). Measuring fraud and earnings management by a case of study: Evidence from an international family business. European Journal of Family Business, 7(1-2), 41-53. https://doi.org/10.1016/j.ejfb.2017.10.001

Rezaee, Z. (2005). Causes, consequences, and deterence of financial statement fraud. Critical Perspectives on Accounting, 16(3), 277-298. https://doi.org/10.1016/S1045-2354(03)00072-8

Rivero, J. (2015). Contabilidad Financiera. Madrid: EDISOFER.

Rodríguez, M.L., Piñeiro, C.S, \& De Llano, P.M. (2014). La tecnología blockchain y su aplicabilidad en la contabilidad. De la partida doble al sistema de triple entrada. Disponible en: https://aeca.es/wp-content/uploads/2014/05/70g.pdf

Rückeshäuser, N. (2017). Do we really want blockchain-based accounting? Decentralized consensus as enabler of management override of internal controls. 13th International Conference on Wirtschaftsinformatik. (WI), February 12-15, 2017, St. Gallen, Switzerland.

Sangster, A, \& Scataglinibelghitar, G. (2010). Luca Pacioli: The father of accounting education. Accounting Education: An international journal, 19(4), 423-438. https://doi.org/10.1080/09639284.2010.501955

Scoll, J. (2014). The Reckoning. New York: Basic Books.

Schmitz, J., \& Leoni, G. (2019). Accounting and auditing at the time of blockchain technology: A research agenda. Australian Accounting Review, 29(2), 331-342. https://doi.org/10.1111/auar.12286

Swan, M. (2015). Blockchain: Blueprint for a new economy. Sebastopol: O'Reilly Media, Inc.

Tan, B.S., \& Low, K.Y. (2019). Blockchain as the data base engine in the accounting system. Australian Accounting Review, 29(2), 312-318. https://doi.org/10.1111/auar.12278

Tapscott, D, \& Tapscott, A. (2016). Blockchain revolution: How the technology behind bitcoin is changing money, business, and the world (1st ed.). New York: Penguin.

Umeh, J. (2018). Beyond Bitcoin and the Blockchain. ITNOW, 60(3), 48-49. https://doi.org/10.1093/itnow/bwy077

Unerman, J, \& O’Dwyer, B. (2004). Enron, WorldCom, Andersen et al.: A challenge to modernity. Critical Perspectives on Accounting, 15(6-7), 971-993. https://doi.org/10.1016/j.cpa.2003.04.002 
Walch, A. (2015). The Bitcoin Blockchain as Financial Market Infrastructure: A Consideration of Operational Risk. New York University Journal of Legislation \& Public Policy, 18(4), 837-889.

Yli-Huumo, J., Ko, D., Choi, S., Park, S, \& Smolander, K. (2016). Where is current research on blockchain technology? A systematic review. PloS one, 11(10), 1-27. https://doi.org/10.1371/journal.pone.0163477

Yu, T., Lin, Z., \& Tang, Q. (2018). Blockchain: The introduction and its application in financial accounting. Journal of Corporate Accounting \& Finance, 29(4), 37-47. https://doi.org/10.1002/jcaf.22365

Intangible Capital, 2021 (www.intangiblecapital.org)

Article's contents are provided on an Attribution-Non Commercial 4.0 Creative commons International License. Readers are allowed to copy, distribute and communicate article's contents, provided the author's and Intangible Capital's names are included. It must not be used for commercial purposes. To see the complete license contents, please visit https://creativecommons.org/licenses/by-nc/4.0/. 